Environment Conservation Journal 15(1 \&2)201-205, 2014

ISSN 0972-3099 (Print) 2278-5124 (Online)

Abstracted and Indexed

\title{
Monthly variation in physico-chemical properties of Kosi River in Almora district, Uttrakhand
}

\author{
Pramod Kumar $\bowtie$, Hem Chandra Upadhyay and Anupama Pandey
}

Received: 01.01.2014

Revised: 06.05.2014

Accepted: 21.05.2014

\begin{abstract}
The present investigation was carried out on the Kosi River, an important tributary of the river Ramgangafrom January 2012 to December 2012. Kosi is a spring fed river. The constituents monitored included water temperature, current velocity, pH, total dissolved solid, total solids, conductivity, dissolved oxygen, free carbon dioxide, total alkalinity and hardness. Throughout the study period, the water was found hard and a significant variation of the rest parameters were observed. The present study also revealed that the physico-chemical parameters showed a great seasonal variation and velocity of water andtotal solids were found to be highest in monsoon season that had a strong impact on other physicochemical factors of the river.
\end{abstract}

Keywords: Impact, Kosi, modest, physico-chemical, seasonal variation

\section{Introduction}

Water is an elixir of life and played an important role in the evolution of life from molecules. The aquatic media, such as lakes, rivers, ponds, stream and coastlines are national wealth for any nation. Therefore, constant efforts are made to exploit them for the benefit of its population. Water quality monitoring is of immense importance to activity involving the use of water bodies in the management of fisheries, water supply, pollution, sewage reservoir and impoundment. Today the lentic and lotic ecosystems are grossly polluted due to excessive exploitation and misuse. It involves the assessment of physico-chemical parameters of water bodies, which is a function expressed as pollution parameters. Life in aquatic environments is largely governed by physico-chemical characteristics and their stability in the ecosystem. The precipitation that is the main source of water is contaminated as soon as it reaches on the earth's surface and during its flow anthropogenic activities in surrounding area further add impurities in it. About one third of the drinking water requirements of the world is obtained from surface sources like rivers, canals and lakes (Das and Acharya, 2003). The studies on the major river ecosystems indicate that the major Indian rivers are grossly polluted,

\section{Author's Address}

Department of Zoology, R.H. Government P.G. College Kashipur, U.S. Nagar (Uttarakhand), India

E-mail: drpramodkumar1975@gmail.com

Copyright by ASEA

All rights of reproduction in any form reserved especially beside the cities (Upadhyaya et al., 1982 and Srivastava, 1992). According to Nautiyal, (1984) and Singh et al., (1994) the $\mathrm{pH}$ value was high in winter and lower in summer and monsoon this may be due to the photosynthetic activity in rivers of the Himalaya. The physico-chemical environment exerts profound effect on its biotic components in an aquatic ecosystem. According to Salaskar and Yeragi, (1997) physical and chemical parameters exert their influence individually and collectively and their interaction creates origin of a bioticcommunity. Therefore it is agreed that a single factor has never acted independently as a limiting factor but only with the interactions with others. In the present work, the attempt was made to analyse the physico-chemical properties such as Temperature, Velocity, $\mathrm{pH}$, DO, Free $\mathrm{CO}_{2}$, Total solids, TDS, Conductivity, Alkalinity, and Hardness etc. from lotic ecosystems in Almora district of Uttrakhand to understand the status of water quality.

\section{Material and Methods}

To analyse physico-chemical parameters, water samples were collected every month. Water samples were collected in dried plastic cans of fivelitre capacity from the marginal areas at 1 to 1.5 meter depthduring morning hours. Shomeswar sampling site was selected and selection was based 


\section{Kumar et al.}

on the point where the water most frequently used by the communities for drinking and other domestic work and anthropogenic activities, the site receiving the sewage, dirt forms washed clothesand animal washing activities, fishing activities, cremation, and other activities in a huge manner. The parameters like water temperature, $\mathrm{pH}, \mathrm{DO}$, TDS, Conductivity, Velocity were analysed at the sampling sites while remaining were analysed in the laboratory using the pertinent literature (Welch, 1948; APHA, 1999 and Khanna and Bhutiani 2004).

\section{Results and Discussion}

Physico-chemical characteristics are very important since they have a profound effect on the diversity of living organisms dwelling in them. The seasonal variations in physico-chemical parameters (Average \pm S.D.) of Kosi River at Shomeswar during January 2012 to December 2012 are represented in the Table-1 \& Fig.-1.Water Temperature is an important factor in the aquatic medium, which determines the quality of water. In the present investigation, maximum water temperature was recorded during the summer and minimum during winter season.The water temperature showed its maximum values in the month of July $21.06 \pm 0.20^{\circ} \mathrm{C}$ whereas minimum $13.90 \pm 0.85^{\circ} \mathrm{C}$ in the month of January. $\mathrm{pH}$ is an important parameter of water, since most of the aquatic organisms are adapted to average $\mathrm{pH}$ and do not withstand abrupt changes (George, 1997). $\mathrm{pH}$ values fluctuated minimum in the month of August $7.30 \pm 0.10$ to maximum $9.06 \pm 0.05$ in the month of January.Alkalinity is the measure of buffering capacity of the water. According to Yellavarthi, (2002) it is generally imparted by the salts of carbonates, bicarbonates, phosphate, nitrates etc.

Table1:Showing average (Mean \pm S.D.) of Kosi River during January 2012 to December 2012

\begin{tabular}{|c|c|c|c|c|c|c|c|c|c|c|}
\hline Month & $\begin{array}{l}\text { Temp. } \\
\left({ }^{0} \mathrm{C}\right)\end{array}$ & $\begin{array}{c}\text { Velocity } \\
\text { (meter/sec.) }\end{array}$ & pH & $\begin{array}{c}\text { DO } \\
\text { (mg/l) }\end{array}$ & $\begin{array}{c}\text { Free } \mathrm{CO}_{2} \\
(\mathrm{mg} / \mathrm{l})\end{array}$ & $\begin{array}{c}\text { Total solids } \\
\text { (mg/l) }\end{array}$ & $\begin{array}{l}\text { TDS } \\
\text { (mg/l) }\end{array}$ & $\begin{array}{c}\text { Alkalinity } \\
\text { (mg/l) }\end{array}$ & $\begin{array}{c}\text { Conductivity } \\
(\mu \mathrm{s} / \mathrm{cm})\end{array}$ & $\begin{array}{c}\text { Hardness } \\
\text { (mg/l) }\end{array}$ \\
\hline Jan & $13.9 \pm 0.85$ & $0.28 \pm 0.03$ & $9.06 \pm 0.05$ & $10.66 \pm 0.15$ & $2.03 \pm 0.15$ & $63.33 \pm 1.52$ & $53 \pm 3$ & $16.66 \pm 4.16$ & $103 \pm 1.73$ & $64.33 \pm 4.04$ \\
\hline Feb & $15.4 \pm 0.45$ & $0.25 \pm 0.04$ & $8.7 \pm 0.2$ & $10.43 \pm 0.15$ & $2.26 \pm 0.15$ & $61.66 \pm 2.08$ & $47.33 \pm 2.51$ & $34.33 \pm 4.04$ & $97.66 \pm 2.51$ & $63.0 \pm 1.0$ \\
\hline Mar & $16.43 \pm 0.45$ & $0.25 \pm 0.01$ & $8.56 \pm 0.25$ & $9.56 \pm 0.25$ & $2.63 \pm 0.15$ & $61 \pm 5.29$ & $46.33 \pm 2.51$ & $49.33 \pm 5.13$ & $96.66 \pm 1.52$ & $55.66 \pm 2.08$ \\
\hline Apr & $18.33 \pm 1.04$ & $0.28 \pm 0.01$ & $8.53 \pm 0.15$ & $9.03 \pm 0.15$ & $2.86 \pm 0.15$ & $70.33 \pm 4.50$ & $55.66 \pm 2.51$ & $65.0 \pm 5.0$ & $104.33 \pm 1.52$ & $49.0 \pm 2.0$ \\
\hline May & $21.03 \pm 0.90$ & $0.26 \pm 0.04$ & $8.43 \pm 0.15$ & $7.86 \pm 0.49$ & $2.86 \pm 0.55$ & $73.33 \pm 4.16$ & $57.66 \pm 2.51$ & $52.0 \pm 3.60$ & $105.0 \pm 2.0$ & $45.0 \pm 3.60$ \\
\hline June & $21.5 \pm 0.20$ & $0.26 \pm 0.01$ & $8.13 \pm 0.15$ & $7.56 \pm 0.49$ & $3.2 \pm 0.34$ & $70.33 \pm 2.51$ & $58.33 \pm 1.52$ & $64.33 \pm 7.76$ & $108.0 \pm 2.0$ & $45 \pm 4.58$ \\
\hline July & $21.06 \pm 0.20$ & $0.47 \pm 0.09$ & $7.86 \pm 0.25$ & $7.43 \pm 0.30$ & $3.56 \pm 0.30$ & $76.3 \pm 1.52$ & $62.0 \pm 3.0$ & $56.66 \pm 11.59$ & $115.0 \pm 5.0$ & $44 \pm 3.60$ \\
\hline Aug & $20.5 \pm 0.10$ & $0.59 \pm 0.008$ & $7.30 \pm 0.10$ & $8.23 \pm 0.56$ & $3.13 \pm 0.58$ & $80.0 \pm 2.0$ & $66.0 \pm 5.29$ & $50.0 \pm 13.22$ & $119.33 \pm 6.65$ & $43.0 \pm 3.60$ \\
\hline Sep & $20.0 \pm 0.2$ & $0.54 \pm 0.01$ & $7.73 \pm 0.25$ & $8.46 \pm 0.32$ & $2.30 \pm 0.20$ & $71.0 \pm 3.60$ & $55.33 \pm 3.51$ & $58.33 \pm 4.04$ & $103.33 \pm 3.51$ & $46.33 \pm 2.51$ \\
\hline Oct & $19.06 \pm 0.40$ & $0.45 \pm 0.030$ & $8.23 \pm 0.30$ & $8.46 \pm 0.15$ & $2.43 \pm 0.20$ & $66.66 \pm 5.85$ & $52.66 \pm 1.52$ & $54.66 \pm 1.52$ & $99.0 \pm 2.0$ & $50.66 \pm 1.15$ \\
\hline Nov & $18.03 \pm 0.45$ & $0.33 \pm 0.02$ & $8.76 \pm 0.15$ & $8.66 \pm 0.25$ & $2.10 \pm 0.10$ & $57.66 \pm 1.52$ & $44.33 \pm 2.30$ & $23.33 \pm 2.88$ & $100.66 \pm 5.85$ & $54.33 \pm 4.04$ \\
\hline Dec & $15.60 \pm 0.52$ & $0.31 \pm 0.02$ & $8.90 \pm 0.10$ & $8.90 \pm 0.10$ & $1.96 \pm 0.30$ & $61.33 \pm 3.21$ & $50.33 \pm 2.30$ & $20.66 \pm 3.05$ & $97.33 \pm 1.15$ & $65 \pm 5$ \\
\hline
\end{tabular}

Total alkalinity was observed maximum in the month of April $65.0 \pm 5.0 \mathrm{mg} / \mathrm{land}$ it was recorded minimum at $16.66 \pm 4.16 \mathrm{mg} / \mathrm{l}$ in January. Dissolved Oxygen is extensively used as a parameter determining the water quality and to evaluate the degree of freshness of lotic ecosystem. The amount of dissolved oxygen fluctuated from a maximum of
$10.66 \pm 0.15 \mathrm{mg} / \mathrm{l}$ in the month of January and minimum in the month of July $7.43 \pm 0.30 \mathrm{mg} / \mathrm{l}$. In the present investigation, the maximum DO was recorded during winter, moderate during monsoon and low during summer. The solubility of DO increases with the decrease in water temperature due to that the value of DO is maximum in winter 
(Kumar and Singh, 2002). Ali,(1999) reported that hardness calculated in theriver water was lowest in the dissolved oxygen variation showsan inverse relationship with water temperature variation.The free $\mathrm{CO}_{2}$ recorded maximum $3.56 \pm 0.30 \mathrm{mg} / \mathrm{l}$ in the month of July and its minimum value $1.96 \pm 0.30 \mathrm{mg} / \mathrm{l}$ in the month of December. Bhatt et al.,(1984)also reported high $\mathrm{DO}$ and low free $\mathrm{CO}_{2}$ August $43.0 \pm 3.60 \mathrm{mg} / \mathrm{land}$ highest in the December $65.0 \pm 5 \mathrm{mg} / \mathrm{l}$.In the context of an aquatic ecosystem, conductivity totally depends upon the concentration of ions in the water. In the present investigation, maximum conductivity was recorded during August $119.33 \pm 6.65 \mu \mathrm{s} / \mathrm{cm}$ and minimum during March concentrations in winter in such hill streams. $96.66 \pm 1.52 \mu \mathrm{s} / \mathrm{cm}$. During summerless flow and Respiratory activities of organisms and high anthropogenic activities is responsible to increase summer temperature accelerated the process of the ionic content, which results in the increased decay of organic matter resulting in the addition of level of conductivity. Similar results were reported high quantities of $\mathrm{CO}_{2}$ into the water.The degree of in river Yamuna (Israili and Ahemad, 1993).

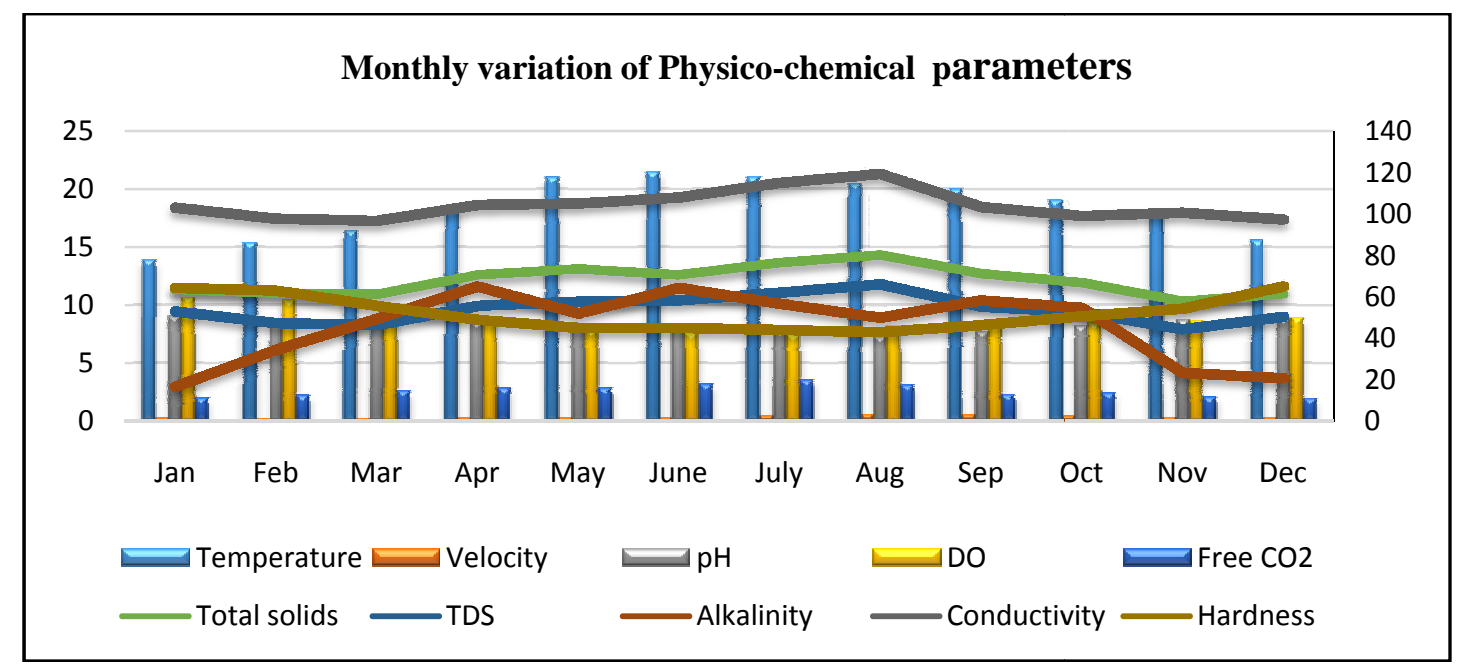

Fig1: Graphical presentations among physico-chemical parameters.

Relationship between hydrological attributes-

The statistical correlation data between the Temperature and velocity were greatly inter hydrological attributes in the Kosi River at correlated. $\mathrm{pH}$ showed an inverse relationship with Shomeswar is represented in Table-2 \& Fig.-2. $\quad$ temperature $(r=-0.779)$.

Table2: Matrix of correlation between Physico-chemical parameters

\begin{tabular}{|c|c|c|c|c|c|c|c|c|c|c|}
\hline Parameters & Temp. & Velocity & pH & DO & $\begin{array}{l}\text { Free } \\
\mathrm{CO}_{2} \\
\end{array}$ & $\begin{array}{l}\text { Total } \\
\text { solids }\end{array}$ & TDS & Alkalinity & Conductivity & Hardness \\
\hline Temp. & 1 & & & & & & & & & \\
\hline Velocity & 0.4667 & 1 & & & & & & & & \\
\hline $\mathrm{pH}$ & -0.7799 & -0.8217 & 1 & & & & & & & \\
\hline DO & -0.9301 & -0.4237 & 0.6482 & 1 & & & & & & \\
\hline Free $\mathrm{CO}_{2}$ & 0.7655 & 0.2569 & -0.6657 & -0.6816 & 1 & & & & & \\
\hline Total solids & 0.7640 & 0.6019 & -0.8347 & -0.6377 & 0.7956 & 1 & & & & \\
\hline TDS & 0.6832 & 0.5698 & -0.7644 & -0.6001 & 0.7563 & 0.9694 & 1 & & & \\
\hline Alkalinity & 0.7710 & 0.2724 & -0.6686 & -0.6105 & 0.7507 & 0.6664 & 0.5455 & 1 & & \\
\hline Conductivity & 0.6531 & 0.5936 & -0.7606 & -0.5713 & 0.7724 & 0.8775 & 0.9086 & 0.4019 & 1 & \\
\hline Hardness & $\begin{array}{l}-0.9609 \\
\end{array}$ & $\begin{array}{l}-0.5182 \\
\end{array}$ & 0.8274 & 0.8341 & -0.8031 & -0.8207 & -0.7232 & $\begin{array}{l}-0.8278 \\
\end{array}$ & $\begin{array}{l}-0.7106 \\
\end{array}$ & 1 \\
\hline
\end{tabular}


Total Alkalinity was positively correlated with temperature, velocity, free $\mathrm{CO}_{2}$, Total Solids, and TDS but showed an inverse relationship with $\mathrm{pH}$ and DO. Conductivity was positively correlated with temperature, velocity, free $\mathrm{CO}_{2}$, Total Solids, and TDS but showed an inverse relationship with $\mathrm{pH}$ and $\mathrm{DO}$.
Hardness shows an inverse relationship with temperature, velocity, free $\mathrm{CO}_{2}$, Total Solids, TDS, conductivity and alkalinity but positive with DO, $\mathrm{pH}$. DO show an inverse relationship with temperature and velocity but positive relationship with $\mathrm{pH}$. Free $\mathrm{CO}_{2}$ shows an inverse relationship with $\mathrm{pH}$ and $\mathrm{DO}$.

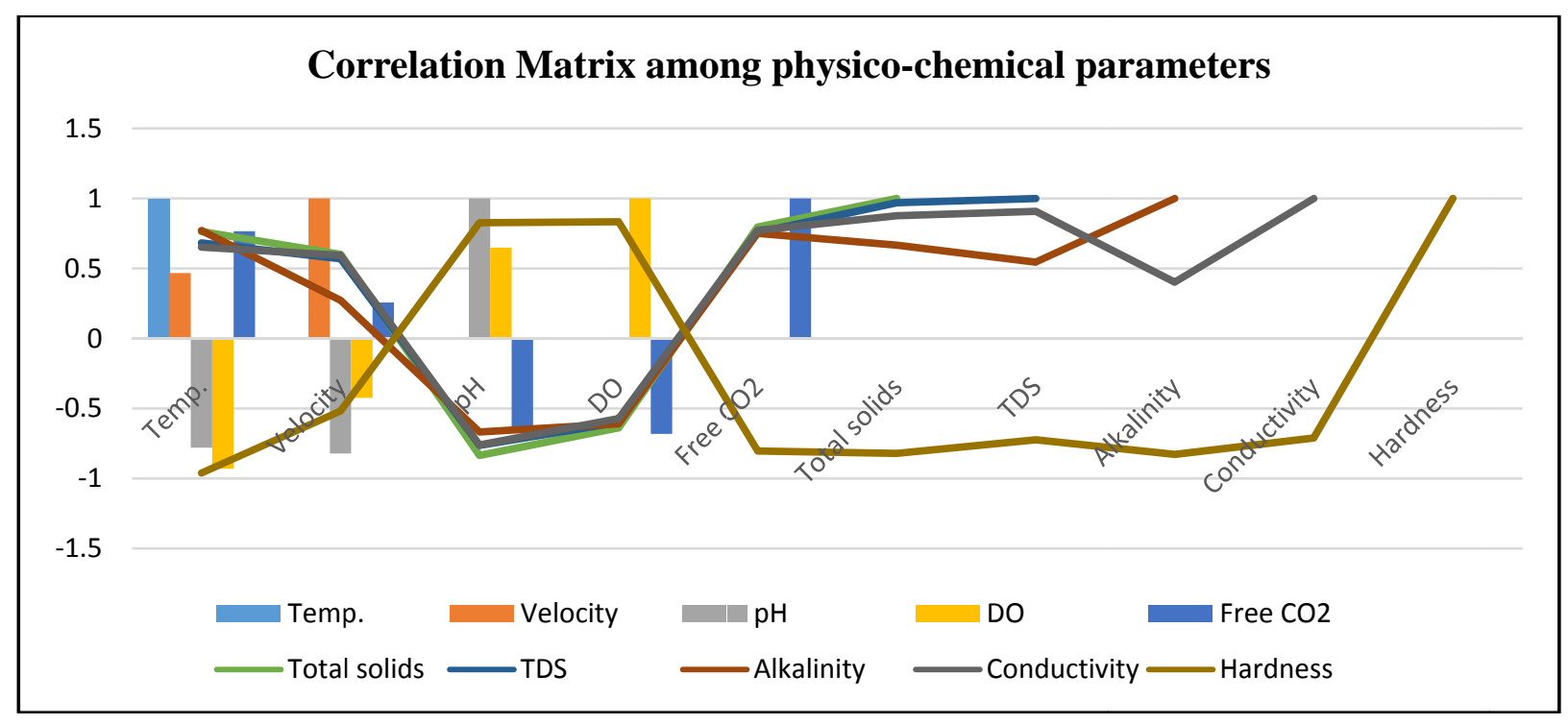

Fig1: Graphical presentations of correlation matrix among physico-chemical parameters

\section{Conclusion}

All over the world aquatic ecosystems are being severely changed \& destroyed at a rate greater than ever known in the human history. Urgent attention is therefore necessary to mitigate pollution problems through monitoring water quality parameters. Thus present study was undertaken \& this study revealed that because of modest or no urbanization the physico-chemical parameters of study area are within the permissible limit.

\section{Acknowledgement}

The authors express sincere thanks to the Head Department of Zoology, Kumaun University, R. H. Government P.G. College, Kashipur, for laboratory facility.

\section{References}

Ali, S. S. 1999.Freshwater FisheryBiology. $1^{\text {st }}$ ed.,Naseem Book Depot,Hyderabad, Pakistan, 108 -114.
APHA 1999. Standard Methods for the Examination of Water and Wastewater. $20^{\text {th }}$ ed., American Public Health AssociationAmerican Water Works Association, Water Environment Federation; Washington, D.C.

Bhatt, S.D., Y. Bisht and Negi, U. 1984.Ecology of the limmofauna in the riverKosi of theKumaunHumalaya. Proc.IndianMatn. Sci. Acid., 50: 395-405.

Das, J. and Acharya, B. C. 2003. Hydrology and Assessment of Lotic Water Quality in Cuttack City, India. J. Water, Air and Soil pollution, 150: 163-175.

George, J. P. 1997. Aquatic ecosystem, structure, degradation strategies for management in: Recent advances in ecobiological research, A.P.H. Publication House, New Delhi. 603.

Israili, A.W. and Ahemad M.S. 1993. Chemical Characteristics of river Yamuna from Dehradun to Agra. Indian $\mathbf{J}$. Environ. HIth. 35(3):199-204.

Khanna, D.R. and Bhutiani, R. 2004.Water analysis at a glance, ASEA publication Rishikesh., 1-116. 
Kumar, Arvind and Singh A. K. 2002.Ecology, Conservation and Management of the River Mayurakshi in SanthalPargana (Jharkhand State) with special reference to effect of sewage pollution on abiotic and biotic potentials., Ecology and Conservation of Lakes, Reservoirs and Rivers., ABD publishers, Rajasthan, India., 1-43.

Nautiyal, P. 1984. Studies on the riverine ecology of torrential waters in the uplands of Garhwal region II. Seasonal fluctuations in diatom density,Proc. Indian Acad. Sci. (Anim. Sci.), 93(7):671-674.

Salaskar, P.B. and Yeragi, S.G. 1997. Studies on water qualitycharacteristics of Shenala lake Kalyan, Maharashtra,India, J. Aqua. Biol., 12(1\&2): 26-31.
Singh G.S. and Singh A.S. 1994. Variation and Correlation of Dissolved oxygen with effluent Quantity and stage of river Ganga at Varanasi (India). Journal Environment Health,36 (2): 79-83.

Srivastava, C. P. 1992. Pollutants and nutrient status in raw sewage, Indian J.Envl. Prot.,18 (2): 109-111.

Upadhyay, R., Dubey, A. P. and Pandey, G. N. 1982.Physicochemical characteristics of the Mahanadi estuary, east coast of India, Pollut. Res., 1: 11-20.

Welch, P.S. 1948. Limnological methods. McGraw Hill book Company Inc. New York. XVIII + 381 pp.

Yellavarthi, E. 2002.Hydrobiological studies of Red Hills Reservoir, North Chennai, Tamilnadu.,J. Aqua. Biol., 17(1):13-16. 